\title{
How Do Infants Disaggregate Referential and Affective Pitch?
}

\author{
René Kager* \\ Utrecht Institute of Linguistics OTS, Utrecht University, Utrecht, Netherlands
}

Infants are faced with a challenge of disaggregating functions of pitch in the ambient language into affective, pragmatic or referential (the latter in tone languages only). This mini review discusses several factors that might facilitate the disaggregation of referential and affective pitch in infancy: acoustic characteristics of infant-directed speech, recognition of vocal affect, facial cues accompanying affective prosody, and lateralization of affective and referential prosody in the brain. It proposes two hypotheses concerning the role of audiovisual cues and brain lateralization

Keywords: infant speech perception, pitch processing, infant language representation, lexical tone acquisition1, Lexical tone perception

This article discusses potential factors to facilitate the disaggregation of referential and affective pitch in infancy: acoustic characteristics of infant-directed speech, recognition of vocal affect, facial cues accompanying affective prosody, and lateralization of affective and referential prosody in the brain. It proposes two hypotheses concerning the role of audiovisual cues and brain lateralization.

Among the many acoustic cues in speech, fundamental frequency (perceived as pitch) is

OPEN ACCESS

Edited by:

Leher Singh,

National University of Singapore,

Singapore

Reviewed by:

Carolyn Quam,

Portland State University,

United States

Feng-Ming Tsao,

National Taiwan University, Taiwan

*Correspondence:

René Kager

r.w.j.kager@uu.nl

Specialty section:

This article was submitted to Language Sciences,

a section of the journal

Frontiers in Psychology

Received: 04 May 2018 Accepted: 10 October 2018 Published: 31 October 2018

Citation:

Kager R (2018) How Do Infants

Disaggregate Referential and Affective

Pitch? Front. Psychol. 9:2093.

doi: 10.3389/fpsyg.2018.02093 arguably the one that, cross-linguistically, has the widest range of linguistic and para-linguistic uses (Gussenhoven, 2004). Universally, pitch signals affective use (for example, express happiness by high average pitch and wide pitch range) and pragmatic use (for example, marking a question by rising pitch is a universal tendency). Exclusively in tone languages, pitch supports referential use by contrasting word meanings (for example, Cantonese /fan/“divide" carries a high-level tone; "angry" a mid-rising tone). Infants born into tone languages (a term which includes "pitch accent" languages; Hyman, 2009) are faced with a challenge of discovering how pitch patterns in the ambient language distinguish different word meanings-hence, they must disaggregate pitch in the input into non-referential and potentially referential information. Infants learning a (nontone) lexical stress language must discover that pitch has no direct, but only indirect referential significance as one of the cues associated with stress (next to other cues, e.g., duration). Detection of the referential significance of pitch poses a critical challenge for infants when they are learning their first words. Yet several studies suggest infants discover the presence/absence of lexical tones before their first birthday. Tone-learning infants retain their initial ability to discriminate tones, while infants exposed to a non-tone language lose it between 6 and 9 months (Mattock and Burnham, 2006; Mattock et al., 2008; Yeung et al., 2013; Liu and Kager, 2014; Götz et al., 2018), before losing the ability to learn tone-to-word associations, which they still possess at 9 months (Yeung et al., 2014), by 18 months (Singh et al., 2014; Hay et al., 2015; Burnham et al., 2018; Liu and Kager, 2018). How are infants able to disaggregate pitch into non-referential affective and referential linguistic information?

Infants' environments are rich in affective content, as infant-directed speech (IDS) is characterized by exaggerated pitch contours reflecting "free vocal expression of emotion" (Trainor et al., 2000), which attracts infants' attention (Cooper and Aslin, 1990; Werker et al., 1994), yet does not a priori facilitate tone acquisition, as it may partially obscure contrastive shapes of tones (Papoušek and Hwang, 1991; Kitamura et al., 2002). Pitch exaggeration in IDS may be partly compensated by tonal hyper-articulation (Liu et al., 2007; Xu Rattanasone et al., 2013; Tang et al., 2017), yet to what extent precisely is an open 
issue. In order to facilitate disaggregation of referential and affective pitch, young infants may draw on their ability to recognize vocal and visual expression of affect.

The ability to interpret speech prosody as having affective value emerges early in life. Pitch contours in IDS presumably carry innately specified affective meanings to young infants, eliciting attention, arousal, approval, and disapproval (see Fernald, 1992, for a review). Neonates show an increase in eye opening responses to happy vocal stimuli as compared to other expressions (angry, sad, neutral), however only for their native language (Mastropieri and Turkewitz, 1999), suggesting prenatal influence on perception of vocal affect. By 5 months, infants reliably discriminate affect, detecting changes in vocal affect from sad to happy (Walker-Andrews and Grolnick, 1983); 7month-olds show different ERP responses to affective (happy or angry) vs. neutral prosody (Grossmann et al., 2005). Yet infants' ability to discriminate affect may not provide a reliable basis for affective-referential pitch disaggregation; perhaps it should be matched by an ability to understand emotion in speech. However, this ability is not developed until 4-5 years (Quam and Swingley, 2012). School-aged children (around age 10) experience difficulties integrating vocal affect with lexical content (Friend, 2000, 2001, 2003; Friend and Bryant, 2000; Morton and Trehub, 2001; Morton et al., 2003). Since the ability to understand emotion in speech develops so slowly, it is worth exploring how affective-referential pitch disaggregation during the first year of life might be supported not only by auditory/vocal cues, but also by visual/facial cues.

By 4-6 months of age, infants in spite of their reduced visual processing can discriminate their native language from other languages partly by relying on visual cues accompanying gestures such as vocalic lip rounding (Weikum et al., 2007). In comparison, visual cues to tonal gestures are weak and unreliable to native listeners (Chen and Massaro, 2008; Hannah et al., 2017). Young infants (4-month-olds) can detect different emotions (happy, angry, sad) when presented with facial-vocal cues (Flom and Bahrick, 2007), an ability emerging prior to affect detection based on unimodal cues (Walker-Andrews, 1997). In light of infants' early sensitivity to facial-vocal cues to affect, the hypothesis can be proposed that affective-referential pitch disaggregation draws on facial affective cues accompanying vocal affect. By labeling pitch information as affective, infants may focus their linguistic attention to residual pitch information that has no clear affective interpretation, which includes referential information.

A neurological marker of affective-referential pitch disaggregation may be obtained in the hemispheric specialization for linguistic and affective pitch. A functional asymmetry between the right hemisphere ( $\mathrm{RH}$; dominant in processing pitch changes and emotional vocalization) and the left hemisphere $(\mathrm{LH}$; dominant in processing speech, in

\section{REFERENCES}

Arimitsu, T., Uchida-Ota, M., Yagihashi, T., Kojima, S., Watanabe, S., Hokuto, I., et al. (2011). Functional hemispheric specialization in processing phonemic and prosodic auditory changes in neonates. Front. Psychol. 2:202. doi: 10.3389/fpsyg.2011.00202 particular segmental information) occurs in neonates (DehaeneLambertz, 2000; Peña et al., 2003). Native listeners process linguistically relevant lexical pitch dominantly in LH (Wang et al., 2001); affective pitch dominantly in RH (Edmondson et al., 1987). Yet hemispheric lateralization of linguistic and affective pitch processing remains a controversial issue (Wong, 2002; Zatorre and Gandour, 2008). Turning to infant studies, early RH specialization for pitch processing is found in neonates (Arimitsu et al., 2011); 3-month-old Japanese infants show stronger $\mathrm{RH}$ responses to natural speech, which includes pitch contours, as compared to prosodically flattened speech (Homae et al., 2006). The processing of lexical pitch is lateralized to $\mathrm{LH}$ in Japanese infants between 4 and 10 months (Sato et al., 2010; see Minagawa-Kawai et al., 2011 for discussion). Plausibly, the disaggregation of affective-referential pitch involves a functional specialization of the brain's hemispheres: general (affective and linguistic) pitch processing starts out in $\mathrm{RH}$, while disaggregation amounts to a lateralization of linguistic pitch processing to $\mathrm{LH}$. Infants' detection of affect, guided by vocal-facial cues, provides the key ability. A second hypothesis is proposed to this effect: the more emotional speech is, the more dominant $\mathrm{RH}$ becomes in speech processing; conversely, less emotional speech implies a decreased role for $\mathrm{RH}$ in pitch processing, enabling a partial shift of pitch processing to $\mathrm{LH}$, the dominant hemisphere for speech processing. This predicts that (the perceived amount of) facial affect influences the locus of pitch processing in the infant brain.

In sum, affective-referential pitch disaggregation by infants may be accomplished by a combination of two (possibly innate) abilities, matching the two hypotheses stated above: (a) recognition of affect in pitch contours and integration of audiovisual (vocal-facial) cues on affect; (b) hemispheric specialization for pitch processing, where $\mathrm{RH}$ acts as "emotion attractor" and LH as "language attractor." Integrating research on early tone perception, audiovisual affect recognition, and hemispheric specialization may open a new perspective on how infants manage to detect the presence/absence of lexical tone in their native language.

\section{AUTHOR CONTRIBUTIONS}

The author confirms being the sole contributor of this work and has approved it for publication.

\section{FUNDING}

The Consortium on Individual Development (CID) is funded through the Gravitation program of the Dutch Ministry of Education, Culture, and Science and the Netherlands Organization for Scientific Research (NWO Grant No. 024.001.003).

Burnham, D., Singh, L., Mattock, K., Woo, P. J., and Kalashnikova, M. (2018) Constraints on tone sensitivity in novel word learning by monolingual and bilingual infants: tone properties are more influential than tone familiarity. Front. Psychol. 8:2190. doi: 10.3389/fpsyg.2017.02190

Chen, T. H., and Massaro, D. W. (2008). Seeing pitch: visual information for lexical tones of Mandarin-Chinese. 
J. Acoust. Soc. Am. 123, 2356-2366. doi: 10.1121/1.28 39004

Cooper, R. P., and Aslin, R. N. (1990). Preference for infant-directed speech in the first month after birth. Child Dev. 61, 1584-1595. doi: 10.2307/1130766

Dehaene-Lambertz, G. (2000). Cerebral specialization for speech and non-speech stimuli in infants. J. Cogn. Neurosci. 12, 449-460. doi: $10.1162 / 089892900562264$

Edmondson, J. A., Chan, J. L., Seibert, G. B., and Ross, E. D. (1987). The effect of right-brain damage on acoustical measures of affective prosody in Taiwanese patients. J. Phon. 15, 219-233.

Fernald, A. (1992). "Human maternal vocalizations to infants as biologically relevant signals: an evolutionary perspective," in The Adapted Mind: Evolutionary Psychology and the Generation of Culture, eds J. H. Barkow, L. Cosmedes, and J. Tooby (New York, NY: Oxford: Oxford University Press), 391-428.

Flom, R., and Bahrick, L. E. (2007). The development of infant discrimination of affect in multimodal and unimodal stimulation: the role of intersensory redundancy. Dev. Psychol. 43:238. doi: 10.1037/0012-1649.43.1.238

Friend, M. (2000). Developmental changes in sensitivity to vocal paralanguage. Dev. Sci. 3, 148- 162. doi: 10.1111/1467-7687.00108

Friend, M. (2001). The transition from affective to linguistic meaning. First Lang. 21, 219-243. doi: 10.1177/014272370102106302

Friend, M. (2003). What should I do? Behavior regulation by language and paralanguage in early childhood. J. Cogn. Dev. 4, 161-183. doi: 10.1207/S15327647JCD0402_02

Friend, M., and Bryant, J. B. (2000). A developmental lexical bias in the interpretation of discrepant messages. Merrill Palmer Q. 46, 342-369.

Götz, A., Yeung, H. H., Krasotkina, A., Schwarzer, G., and Höhle, B. (2018). Perceptual reorganization of lexical tones: effects of age and experimental procedure. Front. Psychol. 9:477. doi: 10.3389/fpsyg.2018.00477

Grossmann, T., Striano, T., and Friederici, A. D. (2005). Infants' electric brain responses to emotional prosody. Neuroreport 16, 1825-1828. doi: 10.1097/01.wnr.0000185964.34336.b1

Gussenhoven, C. (2004). The Phonology of Tone and Intonation. Cambridge: Cambridge University Press.

Hannah, B., Wang, Y., Jongman, A., Sereno, J. A., Cao, J., and Nie, Y. (2017). Crossmodal association between auditory and visuospatial information in Mandarin tone perception in noise by native and non-native perceivers. Front. Psychol. 8:2051. doi: 10.3389/fpsyg.2017.02051

Hay, J. F., Graf Estes, K., Wang, T., and Saffran, J. R. (2015). From flexibility to constraint: the contrastive use of lexical tone in early word learning. Child Dev. 86, 10-22. doi: 10.1111/cdev.12269

Homae, F., Watanabe, H., Nakano, T., Asakawa, K., and Taga, G. (2006). The right hemisphere of sleeping infant perceives sentential prosody. Neurosci. Res. 54, 276-280. doi: 10.1016/j.neures.2005.12.006

Hyman, L. M. (2009). How (not) to do phonological typology: the case of pitchaccent. Lang. Sci. 31, 213-238. doi: 10.1016/j.langsci.2008.12.007

Kitamura, C., Thanavisuth, C., Burnham, D., and Luksaneeyanawin, S. (2002). Universal pitch modifications in infant directed speech: a prelinguistic longitudinal study in a tonal and non-tonal language. Infant Behav. Dev. 24, 372-392. doi: 10.1016/S0163-6383(02)00086-3

Liu, H. M., Tsao, F. M., and Kuhl, P. K. (2007). Acoustic analysis of lexical tone in Mandarin infant-directed speech. Dev. Psychol. 43:912. doi: 10.1037/0012-1649.43.4.912

Liu, L., and Kager, R. (2014). Perception of tones by infants learning a non-tone language. Cognition 133, 385-394. doi: 10.1016/j.cognition.2014.06.004

Liu, L., and Kager, R. (2018). Monolingual and bilingual infants' ability to use nonnative tone for word learning deteriorates by the second year after birth. Front. Psychol. 9:117. doi: 10.3389/fpsyg.2018.00117

Mastropieri, D., and Turkewitz, G. (1999). Prenatal experience and neonatal responsiveness to vocal expressions of emotion. Dev. Psychobiol. 35, 204--214.

Mattock, K., and Burnham, D. (2006). Chinese and English infants' tone perception: evidence for perceptual reorganization. Infancy. 10, 241-265. doi: 10.1207/s15327078in1003_3

Mattock, K., Molnar, M., Polka, L., and Burnham, D. (2008). The developmental course of lexical tone perception in the first year of life. Cognition 106, 1367-1381. doi: 10.1016/j.cognition.2007.07.002

Minagawa-Kawai, Y., Cristià, A., and Dupoux, E. (2011). Cerebral lateralization and early speech acquisition: a developmental scenario. Dev. Cogn. Neurosci. 1, 217-232. doi: 10.1016/j.dcn.2011.03.005
Morton, J. B., and Trehub, S. E. (2001). Children's understanding of emotion in speech. Child Dev. 72, 834-843. doi: 10.1111/1467-8624.00318

Morton, J. B., Trehub, S. E., and Zelazo, P. D. (2003). Sources of inflexibility in 6-year-olds' understanding of emotion in speech. Child Dev. 74, 1857-1868. doi: 10.1046/j.1467-8624.2003.00642.x

Papoušek, M., and Hwang, S. F. C. (1991). Tone and intonation in Mandarin babytalk to presyllabic infants: comparison with registers of adult conversation and foreign language instruction. Appl. Psycholinguist. 12, 481-504. doi: 10.1017/S0142716400005889

Peña, M., Maki, A., Kovacić, D., Dehaene-Lambertz, G., Koizumi, H., Bouquet, F. et al. (2003). Sounds and silence: an optical topography study of language recognition at birth. Proc. Natl. Acad. Sci. U.S.A. 100, 11702-11705. doi: 10.1073/pnas.1934290100

Quam, C., and Swingley, D. (2012). Development in children's interpretation of pitch cues to emotions. Child Dev. 83, 236-250. doi: 10.1111/j.1467-8624.2011.01700.x

Sato, Y., Sogabe, Y., and Mazuka, R. (2010). Development of hemispheric specialization for lexical pitch-accent in Japanese infants. J. Cogn. Neurosci. 22, 2503-2513. doi: 10.1162/jocn.2009.21377

Singh, L., Hui, T. J., Chan, C., and Golinkoff, R. M. (2014). Influences of vowel and tone variation on emergent word knowledge: a cross-linguistic investigation. Dev. Sci. 17, 94-109. doi: 10.1111/desc.12097

Tang, P., Xu Rattanasone, N., Yuen, I., and Demuth, K. (2017). Phonetic enhancement of Mandarin vowels and tones: infant-directed speech and Lombard speech. J. Acoust. Soc. Am. 142, 493-503. doi: 10.1121/1.49 95998

Trainor, L. J., Austin, C. M., and Desjardins, R. N. (2000). Is infant-directed speech prosody a result of the vocal expression of emotion? Psychol. Sci. 11, 188-195. doi: 10.1111/1467-9280.00240

Walker-Andrews, A. S. (1997). Infants' perception of expressive behaviors: differentiation of multimodal information. Psychol. Bull. 121, 437-456.

Walker-Andrews, A. S., and Grolnick, W. (1983). Discrimination of vocal expressions by young infants. Infant Behav. Dev. 6, 491-498. doi: 10.1016/S0163-6383(83)90331-4

Wang, Y., Jongman, A., and Sereno, J. A. (2001). Dichotic perception of Mandarin tones by Chinese and American listeners. Brain Lang. 78, 332-348. doi: 10.1006/brln.2001.2474

Weikum, W. M., Vouloumanos, A., Navarra, J., Soto-Faraco, S., Sebastián-Gallés, N., and Werker, J. F. (2007). Visual language discrimination in infancy. Science 316:1159. doi: 10.1126/science.1137686

Werker, J. F., Pegg, J. E., and McLeod, P. J. (1994). A cross-language investigation of infant preference for infant-directed communication. Infant Behav. Dev. 17, 323-333. doi: 10.1016/0163-6383(94)90012-4

Wong, P. C. (2002). Hemispheric specialization of linguistic pitch patterns. Brain Res. Bull. 59, 83-95. doi: 10.1016/S0361-9230(02)00860-2

Xu Rattanasone, N., Burnham, D., and Reilly, R. G. (2013). Tone and vowel enhancement in Cantonese infant-directed speech at 3,69 , and 12 months of age. J. Phon. 41, 332-343. doi: 10.1016/j.wocn.2013. 06.001

Yeung, H. H., Chen, K. H., and Werker, J. F. (2013). When does native language input affect phonetic perception? The precocious case of lexical tone. J. Memory Lang. 68, 123-139. doi: 10.1016/j.jml.2012. 09.004

Yeung, H. H., Chen, L. M., and Werker, J. F. (2014). Referential labeling can facilitate phonetic learning in infancy. Child Dev. 85, 1036-1049. doi: 10.1111/cdev.12185

Zatorre, R. J., and Gandour, J. T. (2008). Neural specializations for speech and pitch: moving beyond the dichotomies. Philos. Trans. R. Soc. Lond. B Biol. Sci. 363, 1087-1104. doi: 10.1098/rstb.2007.2161

Conflict of Interest Statement: The author declares that the research was conducted in the absence of any commercial or financial relationships that could be construed as a potential conflict of interest.

Copyright (C) 2018 Kager. This is an open-access article distributed under the terms of the Creative Commons Attribution License (CC BY). The use, distribution or reproduction in other forums is permitted, provided the original author(s) and the copyright owner(s) are credited and that the original publication in this journal is cited, in accordance with accepted academic practice. No use, distribution or reproduction is permitted which does not comply with these terms. 